\title{
Hepatology as a distinct specialty - Born in the USA?
}

\author{
Bruce R Bacon MD¹, Paul C Adams MD², Editor-in-Chief
}

$\mathrm{D}_{\mathrm{r}}^{\mathrm{r}}$ Bruce R Bacon is a Professor of Internal Medicine at Saint Louis University School of Medicine (USA) and Director of the Division of Gastroenterology and Hepatology. He was the the purview of gastroenterology. However, at the present time, it has become increasingly apparent that hepatology should be considered a distinct discipline independent from, but closely Chair of the Gastroenterology Board for the American Board of Internal Medicine (ABIM) between 1999 and 2003, and he has been Chair of the Transplant Hepatology Board for the ABIM since its inception in 2004. He was on the Governing Board of the American Association for the Study of Liver Diseases (AASLD) from 1999 to 2005 and was President of the AASLD in 2004. While being involved with these two organizations, he was instrumental to the development of the certifying examination in transplant hepatology, which was administered for the first time in November 2006. More recently, he has become interested in trying to get hepatology as a certified subspecialty to occur after internal medicine without trainees having to go through gastroenterology.

PA: There have been enthusiasts for the certification of hepatology as a distinct specialty in Canada. Many of our training programs in Canada are also certified in the United States, so we have followed the development of hepa-

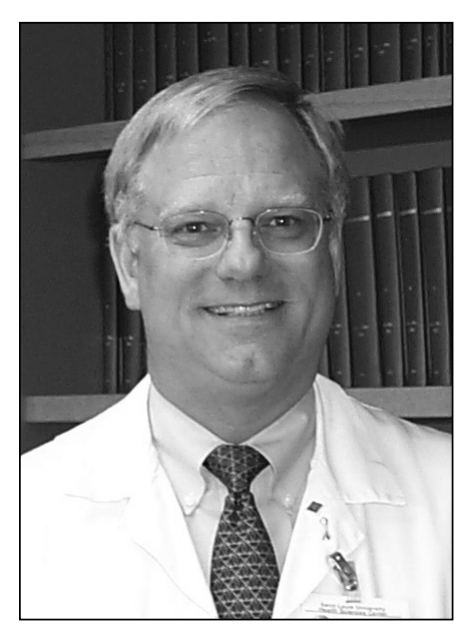

Dr Bruce $R$ Bacon is a Professor of Internal Medicine at Saint Louis University School of Medicine and Director of the Division of Gastroenterology and Hepatology allied with, gastroenterology.

PA: If you do not need certification to practice hepatology, liver transplantation or gastroenterology, what is the need for certification?

BB: It is well established that board-certified physicians have a higher standard of practice than noncertified physicians, so it provides a benchmark for quality of care. Also, in the United States, hospitals are increasingly requiring physicians to be board certified to receive hospital privileges.

PA: What has the response been to the initial examination in advanced/transplant hepatology? BB: Two hundred sixty-one board-certified adult gastroenterologists $(n=214)$ and boardcertified pediatric gastroenterologists $(n=47)$ took the examination in November 2006 with a combined pass rate of $87 \%$.

PA: The fees for liver biopsy, paracentesis and inpatient care are far lower than endoscopic procedures. Are these discrepancies going to be addressed to attract more gastroenterologists into hepatology? tology south of the border with interest. Can you outline the steps that led to the consideration of hepatology as a distinct specialty in the USA?

BB: In 1999, the AASLD performed an analysis of the need for hepatologists within the discipline of gastroenterology. Boardcertified gastroenterologists were queried and it became apparent that they believed that advanced/transplant hepatology was a distinct discipline and more people trained in this area were necessary. That led to an application to the ABIM for consideration of a distinct subsubspecialty called transplant hepatology. At that time, there was not enough interest in hepatology as a subspecialty following internal medicine but rather transplant hepatology as a subdiscipline within gastroenterology. Following approval by the gastrointestinal subspecialty board of the ABIM, this concept was reviewed by the main board of the ABIM and eventually approved. This was then presented to the American Board of Medical Specialties, the overarching board that supervises all specialty boards, and it was approved. Following this approval, a test writing and policy committee was created and questions for the examination were prepared. Finally, the first examination was held in November 2006.

PA: Why is the emphasis on liver transplantation rather than hepatology?

BB: Unfortunately, in my view this was largely a political issue and it was thought that general hepatology remained within
BB: Yes, this is a real problem relative to the economics of hepatology as a distinct subspecialty. I think the solution for this is to create a specialty board in hepatology where training occurs for two to three years and individuals can learn upper endoscopy and management of variceal hemorrhage in addition to liver biopsy, paracentesis and inpatient care. This should go some way toward correcting the economic disparities.

PA: Do you forsee a certification that does not require training in gastroenterology?

BB: The AASLD is beginning to look into the feasibility of hepatology training directly after internal medicine to bypass the need for training in gastroenterology. There have been preliminary discussions with the ABIM and with the leadership of one of our sister societies, the American Gastroenterological Association.

PA: How long will it take for this process to reach completion?

BB: It took eight years from concept to examination for certification in transplant hepatology. I am not sure it will take quite that long for hepatology, although there are several steps along the way that appropriately lengthen the process. As a result, all angles and considerations of such a change are thoroughly debated and reviewed. I am hopeful that by 2015, internal medicine trainees will be able to become hepatologists without a need to become a gastroenterologist first.

\footnotetext{
${ }^{1}$ Saint Louis University, St Louis, Missouri, USA; ${ }^{2}$ University Hospital, London, Ontario

Correspondence: Dr Bruce R Bacon, Division of Gastroenterology and Hepatology, Saint Louis University, 3635 Vista Avenue at Grand Boulevard, St Louis, Missouri 63110-2539, USA. Telephone 314-577-8764, fax 314-577-8125, e-mail baconbr@slu.edu

Received and accepted for publication February 27, 2007
} 


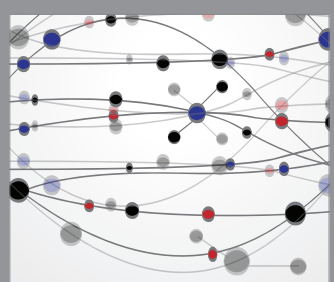

The Scientific World Journal
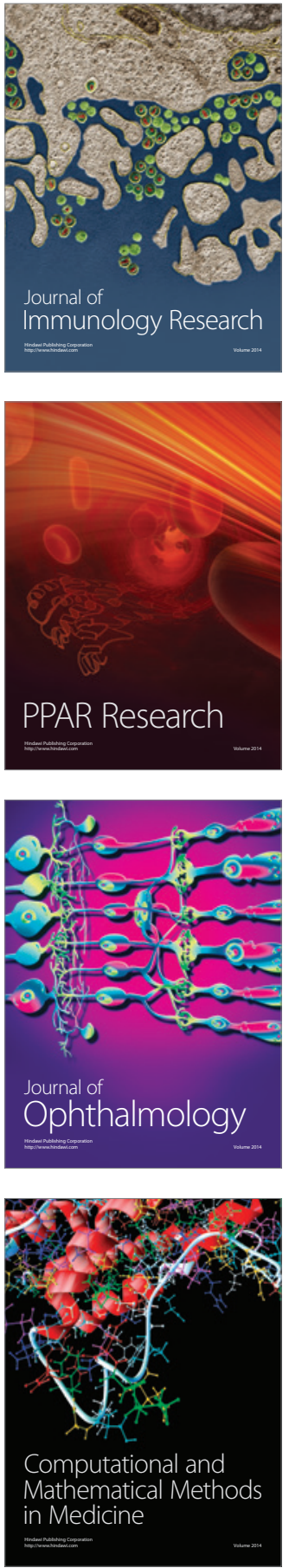

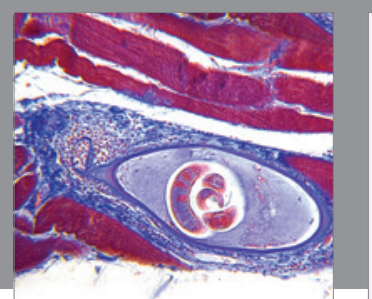

Gastroenterology Research and Practice

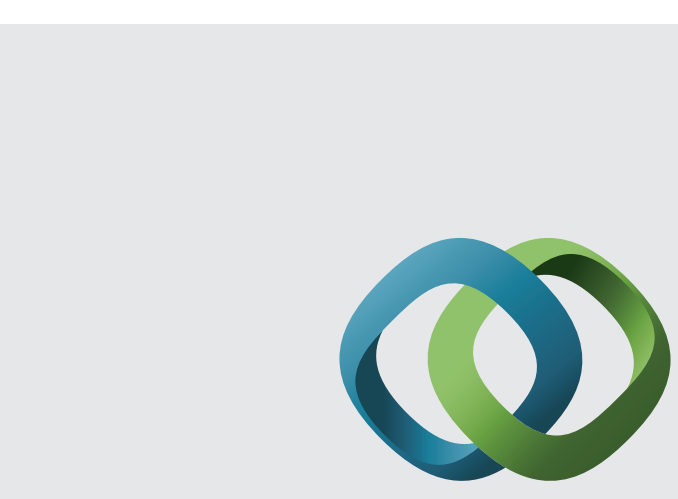

\section{Hindawi}

Submit your manuscripts at

http://www.hindawi.com
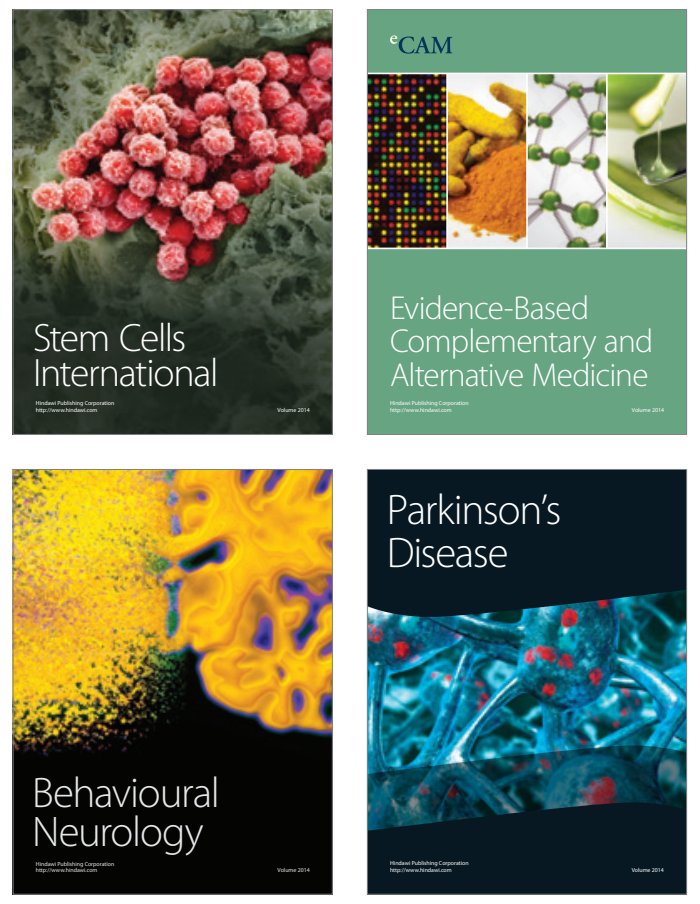
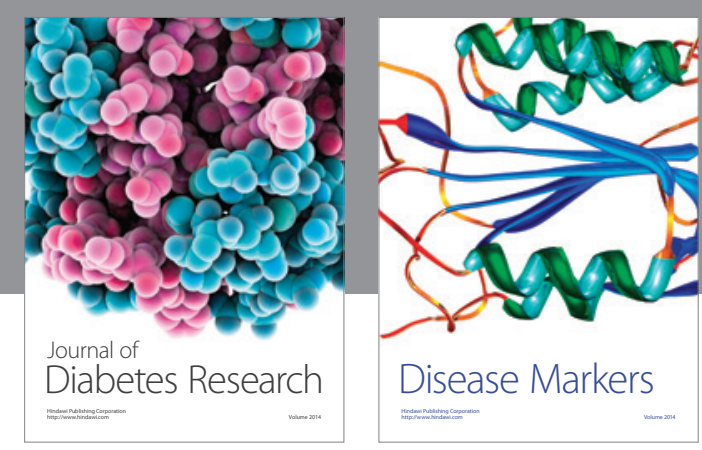

Disease Markers
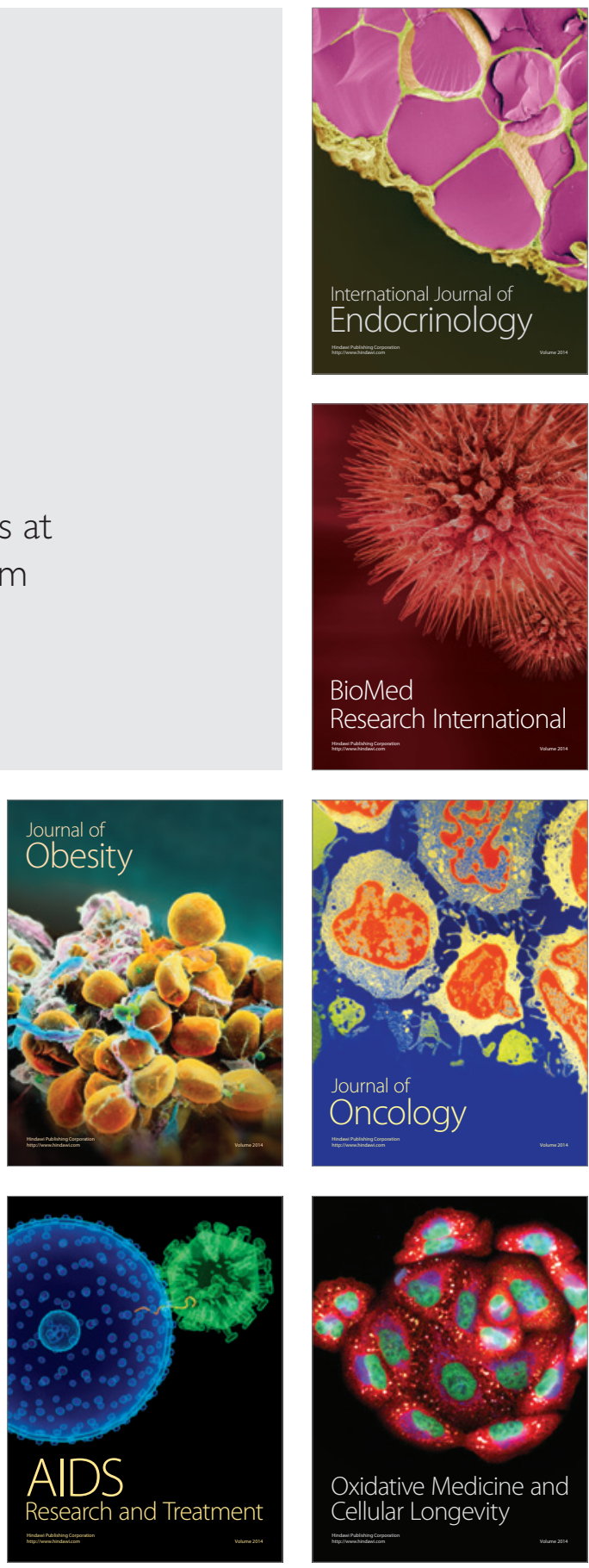